\title{
EVALUATION OF ALIZARIN DYE PENETRATION INTO DENTINAL TUBULES FOLLOWING FINAL RINSE BY Q- MIX AND APPLE VINEGAR: AN IN VITRO STUDY
}

\author{
Samar M. Saied ${ }^{* *} B D S$, Sybel M. Moussa ${ }^{2} P h D$, Nihal A. Leheta ${ }^{3} P h$, Ghada M. \\ Mourad $^{4} P h D$
}

\begin{abstract}
INTRODUCTION: Successful treatment of a root canal aims for removal of microorganisms from the canal. Therefore, intraradicular removal of the smear layer is a remarkable measure for long-established endodontic success.

AIM OF THE STUDY: to assess Alizarin dye penetration into dentinal tubules following Q-Mix, apple vinegar, and 17\% ethylenediaminetetraacetic acid (EDTA) under confocal laser scanning microscope (CLSM).

MATERIALS AND METHODS: Thirty extracted single-canaled mandibular premolars went through decoronating to 15 mm length to undergo cleaning and instrumentation. Then, they were allocated at random into three groups based on the final rinse used: Group I: $10 \mathrm{ml}$ of 17\% EDTA for 1 minute, Group II: $10 \mathrm{ml}$ of apple vinegar for 1 minute, and Group III: $10 \mathrm{ml}$ Q-MIX for 1 minute. All root canals were irrigated by $5 \mathrm{ml}$ Sodium hypochlorite labeled with Alizarin red. Samples were horizontally sectioned and evaluated under CLSM at distinct canal levels. Data were analyzed using (Kruskal Wallis and Friedman’s) Tests.

RESULTS: The three tested groups showed no statistically significant difference with $\mathrm{p}>0.05$. Regarding the coronal and middle thirds of EDTA, ACV, and Q-Mix groups, most of the specimens recorded score 3 (less than $50 \%$ of the whole number of dentinal tubules were penetrated with the dye) while the specimens of apical thirds recorded score 2 (traces of the dye could be seen along the internal canal surface). CONCLUSIONS: Q-Mix, Apple vinegar, and EDTA promoted the penetration through dentinal tubules in the coronal and middle sections superior to the apical section of the root canal.
\end{abstract}

KEYWORDS: Smear layer, Irrigating solutions, Qmix, Apple vinegar, Confocal Laser Scanning microscopy

1 Instructor at the Endodontic Department, Faculty of Dentistry, Alexandria University, Egypt.

2 Professor of Endodontics, Faculty of Dentistry, Alexandria University, Egypt

3 Lecturer of Endodontics, Faculty of Dentistry, Alexandria University, Egypt.

4 Professor of Histology and Cell Biology, Faculty of Medicine, Alexandria University, Egypt.

*Corresponding author

Email: samar.elsayed@alexu.edu.eg

\section{INTRODUCTION}

Effective endodontic treatment chiefly focuses on the reduction of microorganisms and prevents reinfection of the radicular system. Mechanical canal preparation and irrigation using a chemical substance are used simultaneously to clean root canal systems (1).

Such mechanical preparation results in establishing an amorphous layer called "smear layer", that obstructs the dentinal tubules to reach $40 \mu \mathrm{m}$ in depth. This layer influences antagonistically irrigants and medicaments to get inside the infected dentinal tubules, and prohibits the ability of the obturation materials to adapt to the canal walls (2). Thus, a combination of various irrigants is needed to eliminate both components (organic and inorganic) of the structure of smear layer.

Sodium hypochlorite $(\mathrm{NaOCl})$ is the irrigant that is still used worldwide during root canal treatment due to its bactericidal and virucidal activity. It can break down organic tissue as well (3). However, inorganic contents found in the smear layer cannot be eliminated using $\mathrm{NaOCl}$ so, other chelating agents such as ethylenediaminetetraacetic acid (EDTA) 17\% have been used for smear layer removal $(3,4)$.
A new irrigant solution Q-Mix 2 in 1 revealed its capability of smear layer removal in addition to its antimicrobial efficiency. Its composition relies on the presence of a chelating agent of polyaminocarboxylic acid, an antimicrobial agent called bisbiguanide, a surfactant, and finally deionized water. It can be used as a final irrigant instead of EDTA due to its lesser dentin erosion compared to EDTA (4).

Various natural products have been newly proposed for the use as irrigants through canal therapy due to their antimicrobial activity and fewer side effects. The use of apple vinegar (ACV) in the bio-mechanical preparation has also been evaluated and has shown its bactericidal action (5).

Confocal laser scanning microscope (CLSM) is considered a valuable tool that has been recently used in many investigations and research work. When compared to Scanning Electron Microscope (SEM), CLSM gives the benefit of observations being made in near normal conditions with fewer artifacts production. Moreover, it can gather serial optical sections even from thick specimens (6).

Therefore, the purpose of this study was to assess Alizarin dye penetration into dentinal tubules following the use of Q-Mix, apple vinegar, and $17 \%$ 
ethylenediaminetetraacetic acid (EDTA) under confocal laser scanning microscope (CLSM).

In our study, we hypothesized that there would be no difference among Q-Mix, apple vinegar, and 17\% EDTA in the extent of removal of the smear layer when used as final irrigants allowing Alizarin dye to penetrate the dentinal tubules.

\section{MATERIALS AND METHODS Preparation of teeth:}

The current study was applied on thirty mandibular premolar teeth, extracted for periodontal problems. Teeth selected were single canaled with fully developed apices. They were free from calcifications, cracks, root caries, attrition, and external resorption. The selected teeth were scaled to remove debris, calculus, and organic tissues using ultrasonic scaler, and then stored in $0.9 \%$ saline solution.

Preparation of access cavity was carried out in each tooth. Teeth were decoronated using a diamond disc with a straight handpiece and finished using a diamond stone with high speed handpiece to standardize the whole root length to $15 \mathrm{~mm}$. Apical patency was checked by size 10 K-file (Dentsply Maillefer, Ballaigues, Switzerland). Each canal would accommodate 15 K-file (Dentsply Maillefer) as an initial file. In each root canal, a stainlesssteel size $10 \mathrm{~K}$-file was adjusted until the tip becomes just visible apically at the foramen. The file was retracted to be flushed with the apex and by subtracting $1 \mathrm{~mm}$ from the whole root length, the working length was $14 \mathrm{~mm}$ for the prepared specimens.

For shaping the root canals, ProTaper Next rotary system (Dentsply, Maillefer, Ballaigues, Switzerland) were used up to X3 (apical diameter $0.3 \mathrm{~mm}$, taper 0.07). Specimens were irrigated between each instrument with 2 $\mathrm{mL}$ of $2.5 \% \mathrm{NaOCl}$ (Clorox for Chemical Industries, A.R.E). Covering the apex of the root using wax was essential so that the solution could not drip out from the canal through the apical foramen.

Irrigation groups:

Canals have been rinsed using $5 \mathrm{ml}$ of distilled water after being instrumented. Then, the specimens were distributed randomly into three groups of ten teeth each and final irrigation protocol was followed:

Group I (n = 10): $10 \mathrm{ml}$ for 1 minute of 17\% EDTA (CalixE EDTA 17\%, DHARMA RESEARCH, Miami, USA).

Group II (n = 10): $10 \mathrm{ml}$ for 1 minute of apple vinegar conc. 5\% (ACETOdi Mele, Andrea Milano, Napoli, Italy).

Group III (n = 10): $10 \mathrm{ml}$ for 1 minute of Q-Mix (Dentsply Tulsa Dental Specialities, Tulsa, OK, USA).

To ensure even distribution of the solutions, the roots were irrigated with 30 gauge side vented needle (PPH CERKAMED, Stalowa Wola, Poland) with a distance of 1 $\mathrm{mm}$ shorter than working length in an apical-and-coronal direction. Master gutta-percha points corresponding to master file X3 were used for manual dynamic agitation of the final irrigants by applying 100 strokes in a period of approximately $1 \mathrm{~min}$ (7). $5 \mathrm{ml}$ sterile distilled water were used to rinse the canals from any surplus solution and then, they were dried using sterile absorbent paper points.
Confocal laser scanning microscopy:

For fluorescence to be detected under confocal microscopy, $5 \mathrm{ml}$ of $\mathrm{NaOCl}$ (2.5\%) labeled with fluorescent dye of $0.2 \%$ Alizarin red (Sigma Aldrich Coporation, USA) were used as an indicator for evaluating smear layer removal after using the tested irrigating solutions and penetration of the fluorescent dye through the dentinal tubules. $\mathrm{NaOCl}$ labeled with Alizarin dye was applied on all samples for 1 minute accompanied by manual dynamic agitation at a value of 100 strokes in a period of $1 \mathrm{~min}$ for standardization. After drying the canals using sterile paper points, samples were subjected to sectioning in a horizontal manner to be perpendicular to the long axis with the aid of water-cooled microtome saw (Micracut 150, Metkon Metallography, Bursa, Turkey). Samples were cut in $1 \mathrm{~mm}$ thick sections at 3, 5, and $8 \mathrm{~mm}$ from the anatomical apex. Those sections went through grinding to approximately 500 $\mu \mathrm{m}$ thickness and polished using silicon carbide paper. After subjecting those specimens to mounting onto glass slides, they were examined at a magnification of $5 \mathrm{X}$ with wavelength of 540-600 nm with a Leica TCS-SPII confocal laser scanning microscope (Leica, Mannheim, Germany) (Figure 1). Partial images were captured when it was not possible to inspect the entire canal in one image. Photoshop software was then used to put these images together to produce one image. Assessment of the penetration of Alizarin red dye through the dentinal tubules was performed following the scoring criteria shown in Table 1 (8) to detect the effect of the tested irrigating solutions on the smear layer removal.

\section{Statistical analysis}

Comparison of median values of the score system for the studied groups was done using Kruskal Wallis and Friedman's tests. Significance level was set at 0.05 . These were followed by Post-hoc multiple comparisons using Bonferroni adjustment for multiple pairwise comparisons with adjusted significance levels (9) to compare between the different levels of the canal representing the apical, middle, and coronal thirds within the same group.

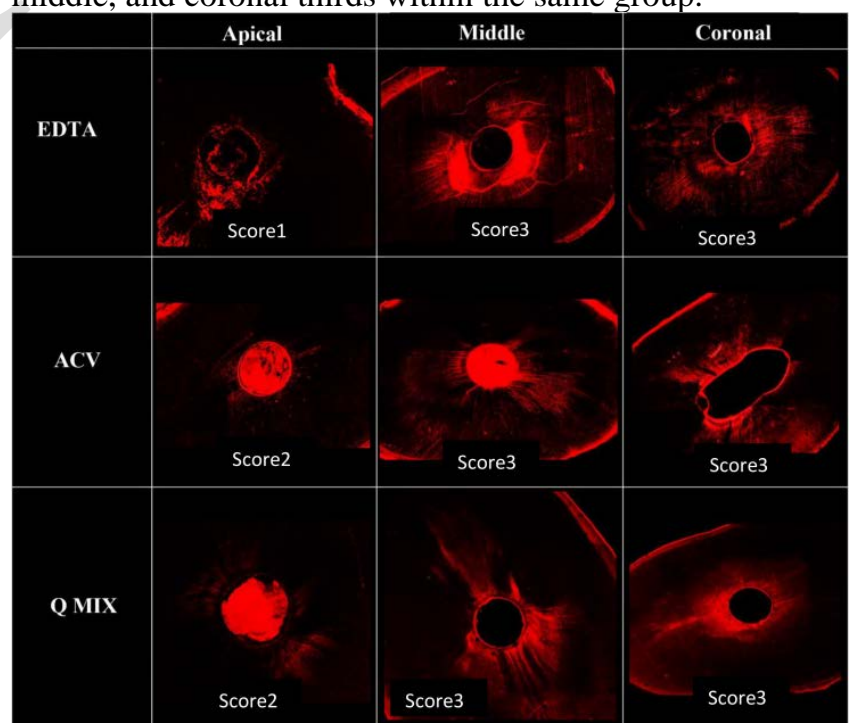

Figure 1: CLSM images representative of dye penetration into dentinal tubules for each group at the apical, middle and coronal thirds. 
Table 1: Scoring criteria for assessment of the dye penetration through the dentinal tubules:

\begin{tabular}{|l|l|}
\hline $\begin{array}{l}\text { Score } \\
\text { no. }\end{array}$ & Description \\
\hline Score 0 & No visible Alizarin. \\
\hline Score 1 & Minor traces of Alizarin. \\
\hline Score 2 & $\begin{array}{l}\text { Traces of Alizarin could be seen along the internal } \\
\text { canal surface. }\end{array}$ \\
\hline Score 3 & $\begin{array}{l}\text { Less than } 50 \% \text { of the whole number of dentinal tubules were } \\
\text { penetrated by Alizarin. }\end{array}$ \\
\hline Score 4 & $\begin{array}{l}\text { More than } 50 \% \text { of the whole number of tubules were } \\
\text { penetrated by Alizarin. }\end{array}$ \\
\hline
\end{tabular}

\section{RESULTS}

The median of the scoring to assess the penetration of Alizarin red dye inside the dentinal tubules is shown in Table 2 and Figure 2 to determine the ability of EDTA, $\mathrm{ACV}$, and Q-Mix to remove the smear layer from the coronal, middle and apical thirds of the canal and to what extent the dentinal tubules could be penetrated.

No statistically significant difference $(\mathrm{p}>0.05)$ was observed among the three tested groups. The coronal and middle third sections of EDTA, ACV, and Q-Mix groups showed similar scores of penetration (score 3 ) that were higher than the apical sections. Most of the apical thirds of the tested groups recorded score 2 (Table 2).

When intragroup comparison was performed, there was a statistically significant difference $(\mathrm{p}<0.05)$ between the apical and both the coronal and middle sections of the canals. Post-hoc multiple comparisons using Bonferroni adjustment was used. Significance level is adjusted at $\mathrm{p}$ value $<0.02$ (Table 3 ).

The penetration in the coronal and middle thirds was significantly higher compared to the apical third in QMix with $p$ value $=0.001$ and 0.005 respectively and ACV with $\mathrm{p}$ value $=0.002$ and 0.002 respectively. There was no statistically significant difference $(\mathrm{p}=1)$ between coronal and middle thirds of the canals for both groups (Table 3 ).

In the EDTA group, Table 2 showed a significant difference $(p=0.03)$ at different levels of the canal walls but after adjusting the level of significance as shown in Table 3, no significant difference ( $>0.02)$ was detected among coronal, middle and apical thirds of the EDTA group

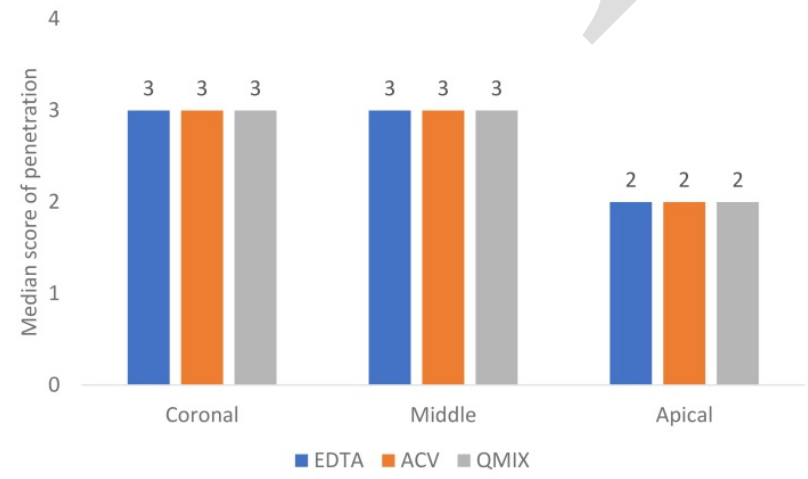

Figure 2: Bar chart showing scoring of irrigant solution penetration in the three studied groups.

Table 2: Scoring of irrigant solution penetration as assessed using Alizarin dye in the studied groups:

\begin{tabular}{|c|c|c|c|c|c|}
\hline & & $\begin{array}{l}\text { Group1 } \\
\text { (EDTA) }\end{array}$ & $\begin{array}{l}\text { Group } 2 \\
(\mathrm{ACV})\end{array}$ & $\begin{array}{l}\text { Group3 } \\
\text { (QMIX) }\end{array}$ & $\begin{array}{l}\text { KWT } \\
\text { (P } \\
\text { value) }\end{array}$ \\
\hline \multirow{5}{*}{ Coronal } & Score 1 & $0(0 \%)$ & $0(0 \%)$ & $0(0 \%)$ & \multirow{5}{*}{$\begin{array}{l}0.18 \\
(0.91)\end{array}$} \\
\hline & Score 2 & $2(20 \%)$ & $0(0 \%)$ & $0(0 \%)$ & \\
\hline & Score 3 & 8 (80\%) & $\begin{array}{l}10 \\
(100 \%)\end{array}$ & 9 (90\%) & \\
\hline & Score 4 & $0(0 \%)$ & $0(0 \%)$ & $1(10 \%)$ & \\
\hline & $\begin{array}{l}\text { Median } \\
\text { (IQR) }\end{array}$ & $\begin{array}{l}3.00 \\
(2.75, \\
3.00) \\
\end{array}$ & $\begin{array}{l}3.00 \\
(3.00, \\
3.00) \\
\end{array}$ & $\begin{array}{l}3.00 \\
(3.00 \\
3.00) \\
\end{array}$ & \\
\hline \multirow{5}{*}{ Middle } & Score 1 & $0(0 \%)$ & $0(0 \%)$ & $0(0 \%)$ & \multirow{5}{*}{$\begin{array}{l}1.86 \\
(0.40)\end{array}$} \\
\hline & Score 2 & \multirow{2}{*}{\begin{tabular}{|l|}
$3(30 \%)$ \\
$7(70 \%)$
\end{tabular}} & $1(10 \%)$ & $1(10 \%)$ & \\
\hline & Score 3 & & $9(90 \%)$ & $9(90 \%)$ & \\
\hline & \begin{tabular}{|l|} 
Score 4 \\
\end{tabular} & $0(0 \%)$ & $0(0 \%)$ & $0(0 \%)$ & \\
\hline & $\begin{array}{l}\text { Median } \\
\text { (IQR) }\end{array}$ & $\begin{array}{l}3.00 \\
(2.00, \\
3.00) \\
\end{array}$ & $\begin{array}{l}3.00 \\
(3.00,3.00 \\
)\end{array}$ & $\begin{array}{l}3.00 \\
(3.00, \\
3.00)\end{array}$ & \\
\hline \multirow{5}{*}{ Apical } & Score 1 & $1(10 \%)$ & $0(0 \%)$ & $1(10 \%)$ & \multirow{5}{*}{$\begin{array}{l}4.58 \\
(0.10)\end{array}$} \\
\hline & Score 2 & $5(50 \%)$ & $7(70 \%)$ & $6(60 \%)$ & \\
\hline & Score 3 & $4(40 \%)$ & $3(30 \%)$ & $3(30 \%)$ & \\
\hline & Score 4 & $0(0 \%)$ & $0(0 \%)$ & $0(0 \%)$ & \\
\hline & $\begin{array}{l}\text { Median } \\
\text { (IQR) }\end{array}$ & $\begin{array}{l}2.00 \\
(2.00, \\
3.00) \\
\end{array}$ & $\begin{array}{l}2.00 \\
(2.00, \\
3.00) \\
\end{array}$ & $\begin{array}{l}2.00 \\
(2.00 \\
3.00) \\
\end{array}$ & \\
\hline \multicolumn{2}{|c|}{$\begin{array}{l}\text { Friedman's test } \\
\text { (P value) }\end{array}$} & $\begin{array}{l}7.40 \\
(0.03 *)\end{array}$ & $\begin{array}{l}15.00 \\
(0.001 *)\end{array}$ & $\begin{array}{l}15.20 \\
\left(0.001^{*}\right)\end{array}$ & \\
\hline
\end{tabular}

KWT: Kruskal Wallis test.

*statistically significant at p value $<0.05$

Table 3: Post-hoc multiple comparisons using Bonferroni adjustment

\begin{tabular}{|l|l|l|l||}
\hline \multicolumn{1}{|c|}{ up } & \multicolumn{1}{c|}{$\begin{array}{c}\text { Region } \\
\text { (subgroup) }\end{array}$} & \multicolumn{1}{c|}{$\begin{array}{c}\text { Co } \\
\text { mpared to }\end{array}$} & \multicolumn{1}{c||}{ value } \\
\hline \multirow{3}{*}{$\begin{array}{l}\text { Group1 } \\
\text { (EDTA) }\end{array}$} & Coronal & Middle & .00 \\
\cline { 2 - 4 } & Middle & Apical & .08 \\
\cline { 2 - 4 } & Coronal & Apical & .04 \\
\hline \multirow{3}{*}{$\begin{array}{l}\text { Group2 } \\
\text { (ACV) }\end{array}$} & Middle & Middle & .00 \\
\cline { 2 - 4 } & & Apical & $.002^{*}$ \\
\hline \multirow{2}{*}{$\begin{array}{l}\text { Group3 } \\
\text { (QMIX) }\end{array}$} & Coronal & Apical & $.002^{*}$ \\
\cline { 2 - 4 } & & Middle & .00 \\
\cline { 2 - 4 } & Middle & Apical & $.001^{*}$ \\
\hline
\end{tabular}

Significance level is adjusted at $\mathrm{p}$ value $<0.02$ 


\section{DISCUSSION}

Chelating agents are considered to be an important step towards successful root canal therapy. Mechanical preparation should be accompanied by solutions used for irrigation to ensure the cleanliness of the intracanal surface and eradication of infection (10). Hence, new irrigants should show their ability in elimination of the smear layer.

This present study was designed to assess Alizarin dye penetration into dentinal tubules following the use of Q-Mix, apple vinegar, and 17\% ethylenediaminetetraacetic acid (EDTA) using confocal laser scanning microscopic analysis.

Several precautions were applied in the study for standardization represented in the total length, initial apical diameter used, gauge of the irrigating needle used, and mechanical preparation.

In the presented study, an irrigating needle of 30 gauge was used to penetrate till the apical part of the root canal. It was found that the irrigant could flow just $1 \mathrm{~mm}$ in depth beyond the tip of the needle (11). Therefore, the needle tip was located at a length of $1 \mathrm{~mm}$ shorter than the working length in our study.

EDTA solution 17\%; which is considered the most commonly used combination with $\mathrm{NaOCl}$ in the elimination of smear layer, has been chosen to be used in this present study since the ionized EDTA is able to chelate calcium ions within the dentin (10). However, it shows cytotoxicity that affects the inflammatory response in periapical lesions. Moon et al (12) reported that prolonged use of EDTA could cause a decrease in microhardness of dentin and decalcification of the peritubular dentin. Hence, more biocompatible irrigants than EDTA was needed.

Another irrigant which was used in our study was Q-Mix. EDTA found in Q-Mix plays an important role in smear layer removal while Chlorohexidine (CHX) gives it its antimicrobial activity $(13,14)$.

In addition, there is no interaction between Q-Mix and remnant of $\mathrm{NaOCl}$ that could form a precipitate of orange-brown color if used directly for the final rinse (15). That's why Q-Mix was chosen in the present study.

Recently, more concern is given towards natural products for root canal cleanliness. Apple cider vinegar is one of the natural acids which is biocompatible and easily available at reasonable cost (5). Dornelles-Morgental et al (16) reported the bactericidal activity of apple vinegar against E. faecalis which is supposed to be an important cause of failure of root canal therapy.

Manual dynamic agitation was used after irrigating the canal with the tested solutions to increase the efficacy of the irrigants inside the root canal with a simple and costeffective technique (7).

The penetration of $\mathrm{NaOCl}$ (2.5\%) labeled with Alizarin red dye was utilized as an indicator for evaluating the ability of the various irrigating solutions to remove the smear layer through tracing the dye through the dentinal tubules under CLSM. The validity of the used method was verified in the pilot study for monitoring and recording the fluorescent dye through the canal space. The former came in accordance with Paragliola et al (8) and Vadhana, Latha, and Velmurugan (11). However, Other studies used sealer labeled with Fluorescent dye and obturation was performed to evaluate the penetration into the dentinal tubules. This method could be a good indicator that was applied for exhibiting the degree of smear layer removal using CLSM analysis $(12,17,18)$. But the root canal obturation stage could affect the penetration ability into the dentin wall due to the pressure that resulted from lateral compaction (19).

Scanning electron microscope (SEM), as well as confocal laser scanning microscope (CLSM) have been recommended to evaluate the efficacy of smear layer removal. CLSM has many advantages over SEM. CLSM can preserve the integrity of the samples as it doesn't need processing and therefore it decreases the artifacts. Moreover, it can help in scanning up to $10 \mu \mathrm{m}$ below the surface of the sample $(11,19)$. Thus, CLSM was preferred and selected for the present study.

On the other hand, Dotto et al (20), Dai et al (21), and Candeiro et al (22) used SEMs. But this methodology is time consuming due to the preparation of the sample for observation under SEM through the gold sputtering and vacuum stages leading to artifacts, thereby compromising the appropriate investigation compared to the CLSM (23).

The null hypothesis of our study was accepted regarding the results that have shown no difference among Q-Mix, apple vinegar, and 17\% EDTA in the extent of removal of the smear layer when used as final irrigants allowing Alizarin dye to penetrate the dentinal tubules. This result came in line with Dai et al (21), and Banode et al (24) who demonstrated that Q-Mix and EDTA had a comparable influence in smear layer elimination regardless of the canal level.

Contrarily, Eliot et al (14) stated that Q-Mix showed a higher cleaning impact compared to 17\% EDTA. The study used different formulas of Q-Mix that presented better effect in coronal and middle thirds of the canals compared to the apical third. This result is attributed to the use of those different formulas with different irrigating periods and an increased number of samples using SEM. Vemuri et al (25) reported also that Q-Mix promoted elimination of debris and smear layer apically compared to $17 \%$ EDTA while both were similar in cleaning the middle and coronal thirds. This result could be due to using a different scoring system used for SEM examination.

Utilization of natural products in Endodontic treatment presented in the use of ACV in this study. The result in our study found no significant difference to be mentioned between ACV and EDTA in cleaning efficacy of the canal walls from debris at different levels. This came in agreement with Ballal et al especially in the coronal and middle thirds (26). Also, Candeiro et al (22) supported the result of this study as apple vinegar when used as an endodontic irrigant was found to be efficient to remove the smear layer. Contrarily, this came in disagreement with Spanó et al (27). Moreover, Kirchhoff et al (28) reported that $17 \%$ EDTA allowed for greater effect on smear layer elimination compared to organic products with no statistical difference among coronal, middle, and apical thirds of the root canals. This could due to the use of solutions in free passage tooth model through the apical foramen, enhancing better wettability of the root dentin and this varies from our study in which the apical foramen was sealed with external wax around the apex to prevent extrusion of the irrigating solution from the root canal. 
When intragroup comparison was performed, a statistical difference was found in our study between apical thirds versus coronal and middle thirds. Coronal and middle thirds showed better penetration while the apical third showed the least amount of penetration. This result could be attributed to insufficient irrigation reaching the apical part. This observation came in line with Jagzap et al (10) and Aydin et al (29).

Any chelating agent exhibits the behavior of being more functional in coronal and middle areas in comparison to the apical ones due to larger diameter and number of dentinal tubules while sclerosis is shown in the apical region so less penetration takes place $(15,29)$. In addition, the viscosity of the different agents might affect their flow through eliminating the smear layer and penetrating the dentinal tubules (30).

One of the limitations of this study, tubular sclerosis of dentinal tubules that were not taken into consideration. Moreover, physical properties of Q-Mix and apple vinegar needed further investigations to evaluate their effect on the penetration depth of those irrigants inside the dentinal tubules. Consequently, more investigations are needed to be able to generalize the results of the existing study to the clinical scenario.

\section{CONCLUSION}

Q-Mix, Apple vinegar, and EDTA achieved effective cleaning ability and penetration in the coronal and middle regions superior to the apical region of the root canal.

\section{CONFLICT OF INTEREST}

The authors deny any conflict of interests related to the current study.

\section{ACKNOWLEDGMENT}

The authors are acknowledging the Centre of Excellence for Research in Regenerative Medicine Applications -CERMA- Alexandria Faculty of Medicine (STDF funded) where the techniques for confocal laser scanning microscopy were implemented.

\section{REFERENCES}

1. Wong DT, Cheung GS. Extension of bactericidal effect of sodium hypochlorite into dentinal tubules. J Endod. 2014;40:825-9.

2. Wang Z, Shen Y, Haapasalo M. Effect of smear layer against disinfection protocols on enterococcus faecalisinfected dentin. J Endod. 2013;39:1395-400.

3. Biel P, Mohn D, Attin T, Zehnder M. Interactions between the Tetrasodium salts of EDTA and 1Hydroxyethane 1,1-Diphosphonic Acid with Sodium hypochlorite Irrigants. J Endod. 2017;43:657-61.

4. Aksel H, Serper A. Concentration and time-dependent effect of initial sodium hypochlorite on the ability of QMix and ethylenediaminetetraacetic acid to remove smear layer. J Conserv Dent. 2017;20:185-9.

5. Mota AC, de Castro RD, de Araújo Oliveira J, de Oliveira Lima E. Antifungal activity of apple cider vinegar on Candida species involved in denture stomatitis. J Prosthodont. 2015;24:296-302.
6. Küçük M, Kermeoğlu F. Efficacy of different irrigation methods on dentinal tubule penetration of Chlorhexidine, QMix and Irritrol: A confocal laser scanning microscopy study. Aust Endod J. 2019;45:202-8.

7. Machtou PP. Manual dynamic activation technique. Clin Dent Rev. 2018;2:21.

8. Paragliola R, Franco V, Fabiani C, Mazzoni A, Nato F, Tay FR, et al. Final rinse optimization: Influence of different agitation protocols. J Endod. 2010;36:282-5.

9. Chen SY, Feng Z, Yi X. A general introduction to adjustment for multiple comparisons. J Thorac Dis. 2017;9:1725-9.

10. Jagzap JB, Patil SS, Gade VJ, Chandhok DJ, Upagade MA, Thakur DA. Effectiveness of three different irrigants-17\% ethylenediaminetetraacetic acid, Q-MIX, and phytic acid in smear layer removal: A comparative scanning electron microscope study. Contemp Clin Dent. 2017;8:459-63.

11. Vadhana S, Latha J, Velmurugan N. Evaluation of penetration depth of $2 \%$ chlorhexidine digluconate into root dentinal tubules using confocal laser scanning microscope. Restor Dent Endod. 2015;40:149.

12. Moon YM, Kim HC, Bae KS, Baek SH, Shon WJ, Lee W. Effect of laser-activated irrigation of 1320nanometer $\mathrm{Nd}$ :YAG laser on sealer penetration in curved root canals. J Endod. 2012;38:531-5.

13. Elakanti S, Cherukuri G, Rao VG, Chandrasekhar V, Rao AS, Tummala M. Comparative evaluation of antimicrobial efficacy of $\mathrm{QMix}^{\mathrm{TM}} 2$ in 1 , sodium hypochlorite, and chlorhexidine against Enterococcus faecalis and Candida albicans. J Conserv Dent. 2015;18:128-31.

14. Eliot C, Hatton JF, Stewart GP, Hildebolt CF, Gillespie MJ, Gutmann JL. The effect of the irrigant QMix on removal of canal wall smear layer: an ex vivo study. Odontology. 2014;102:232-40.

15. Chaudhry S, Yadav S, Talwar S, Verma M. Effect of EndoActivator and Er,Cr:YSGG laser activation of Qmix, as final endodontic irrigant, on sealer penetration: A Confocal microscopic study. J Clin Exp Dent. 2017;9:218-22.

16. Dornelles-Morgental R, Guerreiro-Tanomaru JM, de Faria- Júnior NB, Hungaro-Duarte MA, Kuga MC, Tanomaru-Filho M. Antibacterial efficacy of endodontic irrigating solutions and their combinations in root canals contaminated with Enterococcus faecalis. Oral Surgery, Oral Med Oral Pathol Oral Radiol Endodontology. 2011;112:396-400.

17. Tuncer AK. Effect of QMix 2in1 on sealer penetration into the dentinal tubules. J Endod. 2015;41:257-60.

18. Bolles JA, He J, Svoboda KK, Schneiderman E, Glickman GN. Comparison of vibringe, endoactivator, and needle irrigation on sealer penetration in extracted human teeth. J Endod. 2013;39:708-11.

19. Akcay M, Arslan H, Mese M, Durmus N, Capar ID. Effect of photon-initiated photoacoustic streaming, passive ultrasonic, and sonic irrigation techniques on dentinal tubule penetration of irrigation solution: a confocal microscopic study. Clin Oral Investig. 2017;21:2205-12. 
20. Dotto SR, Travassos RM, De Oliveira EP, de Lima Machado ME, Martins JL. Evaluation of ethylenediaminetetraacetic acid (EDTA) solution and gel for smear layer removal. Aust Endod J. 2007;33:625.

21. Dai L, Khechen K, Khan S, Gillen B, Loushine BA, Wimmer CE, et al. The effect of QMix, an experimental antibacterial root canal irrigant, on removal of canal wall smear layer and debris. J Endod. 2011;37:80-4.

22. Candeiro GT, Matos IB, Costa CF, Fonteles CS, Vale MS. A comparative scanning electron microscopy evaluation of smear layer removal with apple vinegar and sodium hypochlorite associated with EDTA. J Appl Oral Sci. 2011;19:639-43.

23. Tedesco M, Chain MC, Bortoluzzi EA, Garcia LD, Alves AM, Teixeira CS. Comparison of two observational methods, scanning electron and confocal laser scanning microscopies, in the adhesive interface analysis of endodontic sealers to root dentine. Clin Oral Investig. 2018;22:2353-61.

24. Banode AM, Gade V, Patil S, Gade J, Chandhok D, Sinkar R. Comparative scanning electron microscopy evaluation of smear layer removal with $17 \%$ Ethylenediaminetetraacetic acid, 10\% citric acid and newer irrigant QMix: In vitro study. Indian J Oral Heal Res. 2015;1:56-61.

25. Vemuri S, Kolanu SK, Varri S, Pabbati RK, Penumaka R, Bolla N. Effect of different final irrigating solutions on smear layer removal in apical third of root canal: A scanning electron microscope study. J Conserv Dent. 2016;19:87-90.
26. Ballal NV, Kandian S, Mala K, Bhat KS, Acharya S. Comparison of the efficacy of maleic acid and ethylenediaminetetraacetic acid in smear layer removal from instrumented human root canal: a scanning electron microscopic study. J Endod. 2009;35:1573-6.

27. Spanó JC, Silva RG, Guedes DF, Sousa-Neto MD, Estrela C, Pécora JD. Atomic absorption spectrometry and scanning electron microscopy evaluation of concentration of calcium ions and smear layer removal with root canal chelators. J Endod. 2009;35:727-30.

28. Kirchhoff A, Viapiana R, Miranda C, Sousa Neto M, Cruz Filho A. Comparison of the apple vinegar with other chelating solutions on smear layer and calcium ions removal from the root canal. Indian J Dent Res. 2014;25:370-4.

29. Aydın ZU, Özyürek T, Keskin B, Baran T. Effect of chitosan nanoparticle, QMix, and EDTA on TotalFill BC sealers' dentinal tubule penetration: a confocal laser scanning microscopy study. Odontology. 2019;107:64-71.

30. Bukiet F, Soler T, Guivarch M, Camps J, Tassery H, Cuisinier $\mathrm{F}$ et al. Factors affecting the viscosity of sodium hypochlorite and their effect on irrigant flow. Int Endod J. 2013;46:954-61. 